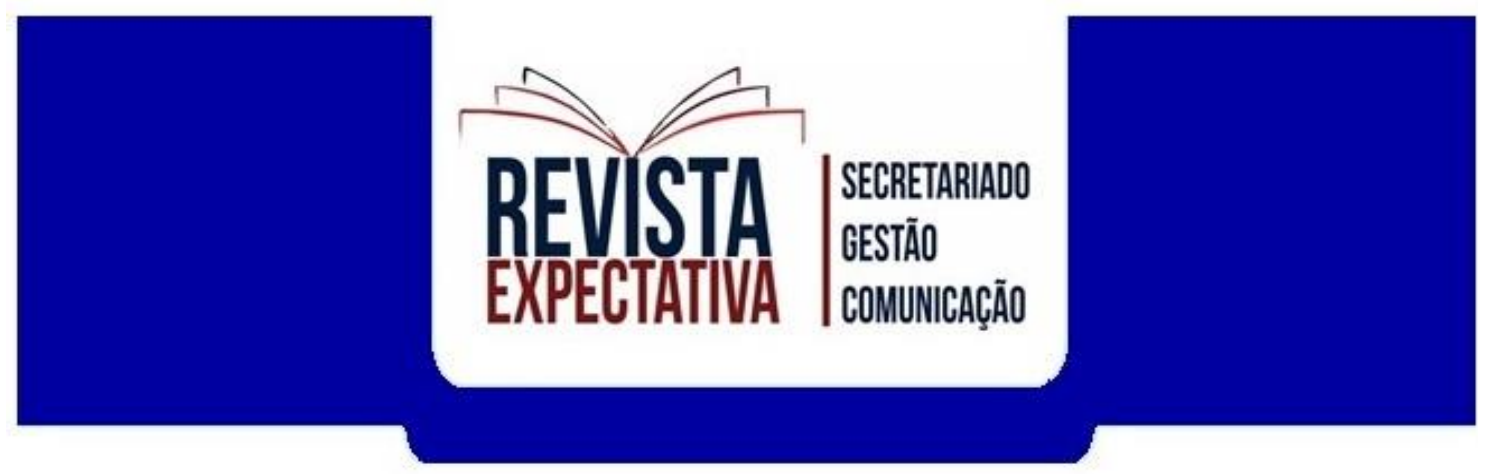

\title{
A EMPREGABILIDADE EM SECRETARIADO EXECUTIVO: O CASO DOS PADRÕES ESTÉTICOS E COMPORTAMENTAIS
}

Deborah Caroline dos Reis Ribeiro ${ }^{1}$, Milena Tais Dias Weber², Ivanete Daga Cielo ${ }^{3}$, Fernanda Cristina Sanches-Canevesi ${ }^{4}$

Resumo: Os estereótipos e estigmas que sempre estiveram presentes para o profissional de secretariado executivo foram responsáveis pela criação de padrões acerca da profissão. Vestir-se elegantemente e formal, cuidar dos cabelos e da alimentação, andar e se portar de forma graciosa são algumas das dicas encontradas em livros publicados da área. Assim, o presente estudo objetiva identificar se os padrões estéticos e comportamentais interferem na empregabilidade dos secretários executivos. A partir da hipótese da discriminação contra os que não seguem essas instruções, surgiu a indagação quanto à influência dos padrões estéticos e comportamentais na empregabilidade dos secretários executivos. Como construto teórico, recorreuse de bibliografias publicadas nos anos de 1980 e 1990 (início da implantação da profissão no país) a fim de identificar a presença de estereótipos nessas obras. Paralelo a isso, discorreu-se sobre os aspectos inerentes a profissão na atualidade, com mesmo olhar para as questões ligadas a estereótipos e estigmas da profissão. Ademais, realizou-se uma pesquisa junto a acadêmicos de um curso de Secretariado Executivo a fim de descobrir suas percepções sobre o tema. Os dados coletados foram analisados de forma descritiva e os principais resultados apontam que padrões estéticos arraigados na profissão são hodiernos nas organizações, podendo interferir negativamente na empregabilidade dos profissionais.

Palavras-chave: Boa aparência. Discriminação. Estereótipo.

\footnotetext{
${ }^{1}$ Discente do curso de Secretariado Executivo Trilíngue pela Universidade Estadual do Oeste do Paraná (Unioeste). https://orcid.org/0000-0003-4867-4461

2 Discente do curso de Secretariado Executivo Trilíngue pela Universidade Estadual do Oeste do Paraná (Unioeste). https://orcid.org/0000-0001-5625-4809

3 Docente do curso de Secretariado Executivo Trilíngue na Universidade Estadual do Oeste do Paraná (Unioeste), campus de Toledo e Doutora em Desenvolvimento Regional e Agronegócio pela Universidade Estadual do Oeste do Paraná (Unioeste). http://orcid.org/0000-0002-9629$\underline{8571}$

$\frac{8571}{4}$ Doutoranda em Educação (Universidade Estadual de Maringá). https://orcid.org/0000-0001$\underline{8593-0925}$
}

Editor: Cezar Roberto Versa

Recebido em: 03/12/2019 - Revisado em: 15/01/2020 - Aprovado em: 21/02/2020

Revista Expectativa- e-ISSN 1982-3029 - v.19 - n.1 - jan./jun. - 2020 


\begin{abstract}
The stereotypes and stigmas that have always been present at the executive secretarial professional have been responsible for creating standards about the profession. Dressing elegantly and formally, caring about hair and alimentation, walking and behaving gracefully are some of the tips found in published books in the area. Therefore, this study aims to identify whether aesthetic and behavioral standards interfere with the employability of executive secretaries. From the hypothesis of discrimination against those who do not follow these instructions, the question arose as to the influence of aesthetic and behavioral standards on the employability of executive secretaries. As a theoretical construct, bibliographies published in the 1980's and 1990's (the beginning of the establishment of the profession in the country) were used in order to identify the presence of stereotypes in these works. Parallel to that, it was discussed the aspects inherent to the profession today, even looking at issues related to stereotypes and stigmas of the profession. In addition, research was carried out with academics from an Executive Secretariat course in order to discover their perceptions on the subject. The data collected were analyzed in a descriptive manner and the main results indicate that aesthetic standards rooted in the profession are nowadays in organizations and may negatively interfere in the employability of professionals.
\end{abstract}

Keywords: Good appearance. Discrimination. Stereotype.

\title{
1 INTRODUÇÃO
}

É indiscutível a presença de estereótipos acerca do profissional de secretariado executivo. O rótulo de ser uma profissão feminina, exclusivamente destinada a tarefas meramente manuais, como atender ao telefone e servir café, e onde a secretária era a amante do seu chefe, data-se desde o início do século passado. Durante a Primeira Guerra Mundial, em 1914, muitos homens precisaram sair de seus postos de trabalho para servir ao exército, assim demandou-se da mão de obra feminina como substituta, de forma que em 1940, já existiam 20 milhões de secretárias no mundo (SABINO; ROCHA, 2004).

Desde então, a profissão passou por significativas mudanças, alterando o perfil técnico e limitado a rotinas, para um profissional multidisciplinar, atuando em setores estratégicos e em processos decisórios das organizações. No entanto, paradigmas do passado ainda assombram a profissão, e sabe-se que a estética tem um papel essencial na construção e manutenção dos 
estereótipos, que impactam no processamento de informações, e influenciam no comportamento profissional (PAIM; PEREIRA, 2011).

Posto isso, tem-se como pressuposto de pesquisa que o profissional de secretariado executivo traz consigo paradigmas acerca de sua aparência e de seu comportamento, e que isso influencia na sua entrada ou permanência no mercado de trabalho, ultrapassando as qualificações profissionais. Portanto, a questão de pesquisa que o presente trabalho quer responder é "os padrões estéticos e comportamentais inerentes ao profissional de Secretariado Executivo, influenciam na sua empregabilidade?".

$\mathrm{O}$ argumento para a realização da pesquisa é fundamentado em estudos, a exemplo de Pires, Fonseca e Padilla (2016) que afirmam que os estereótipos reproduzem práticas discursivas e opressoras que definem a mulher como cuidadora natural e realizadora de tarefas simples e rotineiras, perpetuando a iniquidade de gênero e limitando o potencial disruptivo do crescimento e empoderamento profissional. Faz-se necessário também, a fim de justificar a importância do estudo, o contido no Relatório da Organização Internacional do Trabalho (OIT) apontado que, mesmo que as evidências balizem para uma maior participação das mulheres em diferentes tipos e ambientes de trabalho, no imaginário social ainda existe uma associação imediata das mulheres como uma "força de trabalho secundária", reafirmando velhos estereótipos relacionados às atribuições das mulheres e dos homens no mundo do trabalho (OIT, 2010).

Assim sendo, acredita-se que o tema abordado seja relevante para área de secretariado, composta, em sua grande maioria, por mulheres e envolta de estigmas estereótipos em relação a função. Observa-se um movimento da categoria para a desconstrução desses estigmas e a presença de movimentos, publicidades e hashtags, como o bodypositive, com o intuito de desconstruir padrões impostos principalmente às mulheres. Entretanto, estes padrões ainda são presentes na sociedade e reforçados, muitas vezes pelas mídias e redes sociais, assim como a imagem feminina do profissional de secretariado envolto a estereótipos (FAVRETTO, 2009; PAIM; PEREIRA, 2011).

Este trabalho, que possui como objetivo central identificar se os 
padrões estéticos e comportamentais interferem na empregabilidade dos profissionais de Secretariado Executivo, está estruturado em cinco seções. $\mathrm{Na}$ primeira delas inseriu-se o assunto por meio desta introdução, seguido da fundamentação teórica a qual trará como base registos de livros da área de Secretariado Executivo, além de uma breve revisão sobre a temática dos padrões. A terceira parte apresenta a metodologia aplicada para a realização do estudo, das quais o resultado será apresentado na quarta seção, e por fim, apontam-se as considerações finais do trabalho.

\section{REFERENCIAL TEÓRICO}

\subsection{PADRÕES IMPOSTOS AOS SECRETÁRIOS EXECUTIVOS}

A construção histórica dos estereótipos vinculados aos profissionais de secretariado executivo pode ser percebida na produção de livros da área. Livros como "Secretária de Sucesso" (PARKER PUBLISHING COMPANY, 1981), "Manual prático para secretárias, comissários e modelos" (GRION; PAZ, 1998) e "Profissão: Secretária" (RIBEIRO, 1990) perpetuam o estereótipo da profissão ser feminina. Em todas estas obras há pelo menos um capítulo inteiro dedicado a dicas e instruções de como se vestir, se alimentar, se exercitar, e outros atributos relacionados ao ambiente de trabalho. As justificativas para a reincidência desse assunto nestas obras seria porque "como assistente confidencial de um diretor, sua aparência não só reflete você [secretária], como também seu chefe e sua firma" (PARKER PUBLISHING COMPANY, 1981, p. 53) e ainda que é sempre bom ver e conviver com o belo e bonito, e por essa razão "a boa aparência é um dos primeiros requisitos exigidos pela empresa, em relação a seus funcionários" (RIBEIRO, 1990, p.165). No entanto, o que seria a boa aparência?

Damasceno (2000) analisou em seu artigo exigências em anúncios de vagas de trabalho durante a década de 40 no Brasil, e percebeu que os empregadores revelavam uma preferência por mulheres brancas para os serviços domésticos. A autora constatou então que "a cor submerge sob a rubrica boa aparência" (DAMASCENO, 2000, s/p), ou seja, o termo estava 
relacionado a cor da pele, mais precisamente, branca. Desta forma, constatouse um favoritismo em relação à contratação de empregados brancos em cargos de front office, ou seja, que exigia uma maior exposição e interação com pessoas, sejam elas clientes ou chefes.

É possível perceber, portanto, que este comportamento racista explícito perdurou até o fim do século passado.

Os jornais de grande circulação publicavam até os anos noventa anúncios de emprego que traziam de forma flagrante este critério [a boa aparência] para o preenchimento das vagas de emprego, sobretudo quando envolviam alguma forma de contato com o público. As empresas deixavam explícito que além da formação acadêmica, experiência profissional e a competência técnica, a aparência física era fundamental para a contratação do candidato (PAIM; PEREIRA, 2011, p. 5).

Apesar de se saber que o racismo está enraizado na sociedade, atualmente, em decorrência da militância do movimento negro e da implementação de leis que combatem o preconceito, este não é mais visto de forma tão explícita no Brasil (PAIM; PEREIRA, 2011). Evidencia-se que boa aparência não está mais exclusivamente relacionado a cor de pele e etnia, assim sendo, torna-se necessária a ressignificação do termo para os dias atuais.

Entretanto, a cobrança de uma boa aparência atualmente submerge pela imposição de padrões estéticos, já que estes estão presentes na sociedade de forma velada. Estes "são definidos com base no que é considerado 'belo' ou 'feio', conceitos absolutamente subjetivos e que variam em virtude da cultura e do período histórico" (NASCIMENTO; ALKIMIN, 2013, $\mathrm{s} / \mathrm{p}$ ). Boris e Cesidio (2007, p. 454) definem cultura como o modo de vida de toda sociedade, "cujos costumes de conduta, comportamentos e formas de pensar são compartilhados e transmitidos pelas pessoas que a compõem e passados de uma geração a outra". Logo, a cultura é a principal culpada pela criação de padrões, e tudo e todos que não correspondem a esta exigência são excluídos e se tornam marginalizados perante a sociedade.

Ao se tratar da cultura atual brasileira, de acordo com Nascimento et al. (2013) quando se fala em corpo belo, ou seja, corpo padrão, a referência são pessoas brancas, magras, mas não demais, e altas, também não muito, 
excluindo quem quer que seja gordo ou, baixo ou muito alto, e negro. Isso é refletido de forma pontual no mercado de trabalho, onde,

[...] muitas empresas determinam regras que interferem na aparência do trabalhador, como o uso ou não de maquiagem, a proibição do uso de barba, bigode, cavanhaque ou costeleta, o uso de cabelos afro, longos ou curtos, a proibição do uso de brincos, tatuagens ou piercings, dentre outras infinidades de situações que variam de empresa para empresa, considerando as peculiaridades de cada atividade econômica (NASCIMENTO; ALKIMIN, 2013, s/p).

O preconceito por trás de cada uma dessas características é algo muito presente na sociedade brasileira há séculos, mas foi se modificando ao longo do tempo. A relação boa aparência e racismo moderno, por exemplo, é geralmente expressada de formas mais implícitas, não se vê mais vagas de emprego que exijam profissionais brancos (DAMASCENO, 2000; CARMO, 2011). No entanto, o cabelo afro, como citado acima, ainda é muito discriminado e muitas vezes relacionado à falta de cuidado e de higiene. Paim e Pereira (2012) acrescentam que adereços e estilos de penteados característicos da cultura negra, como dreadlocks, megahair e tranças, também são marginalizados.

Quanto à tatuagem e o piercing, ambos sempre foram referenciados como características da juventude e de rebeldes, transmitindo uma falta de profissionalismo. Carmo (2011) realizou uma pesquisa com o intuito de descobrir se esses adornos impactavam na contratação de funcionários do setor de hotelaria, cargo de front office, assim como o Secretariado Executivo. Evidenciou-se que alguns hotéis alegaram que "profissionais com esse perfil participam somente das primeiras etapas do processo de seleção, sendo descartados como funcionários em potencial" (CARMO, 2011, p.91).

Damasceno (2000) afirma que, durante a década de 40, a boa aparência como pré-requisito era predominante para o sexo feminino, apesar de existir também para os homens. Nota-se então uma maior ênfase e cobrança de padrões estéticos sobre as mulheres do que sobre os homens, que acontece até os dias atuais. Boris e Cesidio (2007) explicam que isso iniciou-se com as transformações históricas e culturais vivenciadas pelas mulheres, levando-as a uma nova construção da subjetividade feminina. A partir do século $X X$, a valorização da estética de seu corpo fora profundamente 
reforçada pelos meios de comunicação, causando "uma banalização do corpo da mulher, pois a mídia o expôs em propagandas, revistas, jornais, programas de TV etc., a fim de estabelecer um padrão de corpo feminino" (BORIS; CESÍDIO, 2007).

Consequentemente, por ter sido rotulada como uma profissão feminina por muito tempo, incorporou-se à cultura da estética como uma característica intrínseca aos profissionais de secretariado executivo, porém de forma mais intensa à profissional mulher. É possível perceber isso no trecho da obra de Parker Publishing Company (1981) em que se é discutido o ideal e o não ideal para cada tipo de corpo: alta e esbelta, tipo mignon, busto pequeno, quadris largos e gordinha. Para este último é explanado que:

\begin{abstract}
Não se deve usar roupa justa de qualquer tipo (ela somente acentuará suas proporções); Listras horizontais, em estampados grandes e xadrezes (isso exagerará suas proporções); Tecidos engomados e brilhantes, colantes (tudo isso atrairá a atenção para o seu problema de peso). [...]; Vestidos sem mangas (seus braços não são os seus melhores pontos) (PARKER PUBLISHING COMPANY, 1981, p.56)
\end{abstract}

De forma contrária, o livro ainda aborda os "sim" para as gordinhas, ou seja, escolha de roupas e acessórios sob o pretexto de que "diminuirão suas proporções", "fará a parecer mais magra" e ainda "V. [você] não vai querer chamar a atenção para qualquer detalhe; V. [você] só quer que sua roupa não pareça tão triste" (PARKER PUBLISHING COMPANY, 1981, p.56).

Destarte, no livro de Grion e Paz (1998) também se observa o preconceito contra pessoas gordas em sentenças disfarçada de dicas e sugestões. No tópico Saúde e Alimentação os autores abordam que:

A ingestão de maior número de calorias do que se consome resultará, logicamente, na formação de tecido adiposo (gordura), o qual se acumulará ao redor dos quadris, barriga, nádegas, seios e coxas. Portanto, é interessante fazer um pequeno (ou grande) sacrifício e seguir uma dieta equilibrada [...] (GRION; PAZ, 1998, p. 54).

Além da pressão estética, os profissionais de secretariado executivo, principalmente do sexo feminino, lidam também com a obrigação de se encaixar em um padrão de comportamento. Já que a profissional é a anfitriã do escritório e o "amortecedor" para seu chefe é esperado que ela seja equilibrada 
e graciosa, além de "nunca ela esquecerá que é uma dama" (PARKER PUBLISHING COMPANY, 1981, p. 14). Ainda, elas devem possuir atitudes simpáticas e elegantes, enfatizando os gestos graciosos e harmoniosos, uma vez que "a gesticulação pausada e comedida é sinal de segurança e personalidade equilibrada", e evitando a gesticulação exagerada, pois esta não permite "exteriorizar e transmitir qualquer charme" (GRION; PAZ, 1998, p. 121 122). Além disso, é recomendado que se tenha "elegância ao andar, sentar e dos próprios gestos, além de demonstrarem organização interior, atestam boas normas de educação, contrastando com atitudes desleixadas e descuidadas" (RIBEIRO, 1990, p. 93).

Como já abordado aqui anteriormente, por se tratar de uma profissão que ainda é socialmente vista como feminina, o secretariado executivo carrega estereótipos e preconceitos femininos. Isto posto, a mulher sempre fora caracterizada como "natureza, emoção, amor e intuição", enquanto aos homens foram destinados a "cultura, política, razão, justiça e poder" (COLLING, 2004, p. 14). Lakoff (2010) partilha deste pensamento ao apresentar que possibilitar formas de se expressar mais fortes aos homens do que as mulheres, somente perpetua o lugar de poder desse primeiro.

Este desiquilíbrio nas relações de poder submete a mulher a características socialmente construídas como femininas:

Se ela [mulher] se recusa a falar como uma dama, é ridicularizada e sujeita à crítica de não ser feminina; se ela aprende, é ridicularizada por não conseguir pensar claramente, por não conseguir tomar parte em uma discussão séria: em certo sentido, como sendo menos do que um ser humano completo. Essas duas escolhas que uma mulher tem [...] são extremamente dolorosas (LAKOFF, 2010, p. 16).

Assim, o comportamento que fora ensinado aos secretários como o adequado para a profissão, como a graciosidade, simpatia e elegância, se tornou um padrão de comportamento, imbuído a um misto de submissão, retração da empregabilidade do profissional.

\subsection{EMPREGABILIDADE EM SECRETARIADO EXECUTIVO}

Percebeu-se até aqui que os padrões estéticos e os comportamentais 
estão há muito tempo ditando as regas do secretariado executivo. Para Paim e Pereira (2011), as empresas interpretam um papel importante nessa imposição de padrões estéticos perpetuando o estereótipo através das normas de conduta e da cultura organizacional. Como tentativa de vetar a exclusão de pessoas que não se encaixam nestes padrões, a Presidência da República redigiu a Lei $\mathrm{n}^{\circ}$ 9.029, de 13 de abril de 1995, onde alega ser "proibida a adoção de qualquer prática discriminatória e limitativa para efeito de acesso à relação de trabalho, ou de sua manutenção" (BRASIL, 1995). Contudo, entende-se que as limitações desta lei impedem que ela auxilie efetivamente contra a imposição destes padrões, já que ela não exclui do empregador o seu direito de autonomia, livre inciativa e liberdade contratual, devendo-se considerar os requisitos da escolha, como, por exemplo, se ele é embasado em estereótipos e preconceitos, ou não (NASCIMENTO; ALKIMIN, 2013).

Assim, visto que os empregadores possuem a liberdade de contratar e manter profissionais com as características que eles melhor preferem, discussões acerca da relação entre estereótipos e empregabilidade do profissional de Secretariado Executivo, tornam-se pertinentes.

Rodrigues et al. (2016) entende empregabilidade como atitudes realizadas por profissionais para desenvolver habilidades e procurar conhecimento, com o objetivo de garantir um espaço no mercado de trabalho. Já Nascimento et al. (2007, p. 22) define empregabilidade como "uma real chance de uma pessoa empregada manter seu emprego, ou, se desempregada, conquistar uma vaga no mercado de trabalho". No entanto, para a presente pesquisa, escolheuse utilizar a definição de Carvalho (2002, apud RODRIGUES et al, 2016) o qual conceitua a empregabilidade como sendo todas as características que um sujeito precisa ter para desenvolver a fundamental habilidade de se adaptar e se enquadrar no mercado de trabalho globalizado.

Devido às mudanças oriundas da globalização, as profissões foram instigadas a passarem por transformações e ressignificações, impondo aos profissionais a busca constante por qualificações para poderem competir no mercado de trabalho. O secretário executivo, por exemplo, deixou de ser aquele que realizava apenas tarefas mecânicas e pouco perspicazes e passou 
a desenvolver atitudes estratégicas que exigiam um conhecimento dinâmico do seu ambiente organizacional. Essas atitudes são identificadas como proatividade, criatividade, comprometimento, flexibilidade, empatia, extroversão, bom senso, liderança, iniciativa, inteligência emocional e cultura global (SAVIANI, 1997 apud. NASCIMENTO et al., 2007; RODRIGUES et al. 2016).

Dito isso, o profissional de Secretariado Executivo deve ter competência para desempenhar um papel multifuncional dentro da organização, porém por muitas vezes ele acaba se tornando refém de padrões, estereótipos e preconceitos impostos à profissão. Quanto as mulheres de um modo geral, de acordo com Sousa et al. [2018 ou 2019], a boa aparência tem sido uma exigência recorrente para que elas mantenham sua empregabilidade.

\footnotetext{
As empresas exigem que elas sigam um padrão estético, que estejam sempre bonitas, não importando se esta premissa inferiorize sua condição feminina. Os empregadores são influenciados pela mídia social, que preconizam a necessidade de expor mulheres exuberantes no ambiente de trabalho, bem como pela persuasão cultural das relações sociais (SOUSA et al., [2018 ou 2019], p. 1).
}

Da mesma maneira acredita-se que essa discriminação se reflete também na profissão de secretariado executivo, em que os secretários, principalmente do sexo feminino, são muitas vezes julgados pela aparência e postura antes mesmo de suas habilidades, influenciando diretamente na sua empregabilidade. No entanto, para verificar se assim realmente acontece na prática, realizou-se uma pesquisa de campo que será apresentada e discutida nas seções seguintes.

\section{PROCEDIMENTOS METODOLÓGICOS}

Considerando que o tema escolhido ainda é pouco explorado na área de secretariado, optou-se por adotar uma pesquisa de caráter exploratório, uma vez que esta tem o objetivo de "proporcionar visão geral, de tipo aproximativo, acerca de determinado fato" (GIL, 2008, p. 27). Quanto à abordagem do problema, este trabalho pode ser considerado uma pesquisa de cunho predominantemente qualitativo, por se priorizar o conteúdo dos dados e não 
seu volume. Decidiu-se escolher essa abordagem também pela grande relevância que representa para estudos de relações sociais, no qual este estudo se enquadra, devido a "mudança social acelerada e a consequente diversificação das esferas de vida [que] fazem com que, cada vez mais, os pesquisadores sociais enfrentem novos contextos e perspectivas sociais" (FLICK, 2009, p. 21).

Por se tratar de um assunto comum e de ciência dos entrevistados, optou-se por realizar os procedimentos desta pesquisa através do levantamento, mais especificamente da entrevista semiestruturada, ou semipadronizada. Assim, os pesquisados puderam expressar suas posições de forma espontânea, seguidas por suas ideias implícitas sobre o assunto abordado (FLICK, 2009, p. 149).

A população pesquisada foram os acadêmicos matriculados no curso de Secretariado Executivo da Universidade Estadual do Oeste do Paraná (Unioeste) no campus de Toledo, o que totalizou em 127 alunos. Entretanto, dado o objetivo do presente estudo, optou-se por entrevistar apenas aqueles acadêmicos que já estavam no mercado de trabalho, desempenhando funções nas áreas administrativas e secretariais. A partir desse recorte, a amostra ficou composta por um grupo de 34 graduandos. Cabe destacar que, para a identificação dessa amostra, aplicou-se um breve questionário a todos os acadêmicos do curso. Em seguida entrou-se em contato com os acadêmicos da amostra para falar sobre a entrevista e marcar um momento para que ela fosse realizada.

Vale ressaltar que, por se tratar de uma entrevista semiestruturada, algumas modificações aconteceram conforme surgiu necessidade, no entanto, sem alterar o sentido das questões. As entrevistas foram realizadas no mês de junho de 2019 nas dependências da Unioeste, de forma individualizada, onde os entrevistados foram nomeados de $A$ à $U$, para manter o sigilo de suas identidades.

Considerando o caráter qualitativo da pesquisa, o fechamento amostral ocorreu pelo processo intitulado saturação teórica, que suspende a inclusão de novos participantes quando os dados obtidos, passam a apresentar, na avaliação do pesquisador, certa redundância ou repetição, não mais 
contribuindo significativamente ao aperfeiçoamento da reflexão teórica fundamentada nos dados que estão sendo coletados. Ou seja, as informações fornecidas pelos novos participantes da pesquisa pouco acrescentariam ao material já obtido (FONTANELLA; RICAS; TURATO, 2008). Assim, após alcançar a quantidade de 21 entrevistas, percebeu-se saturação amostral, com uma amostra de $61,7 \%$, e encerraram-se as entrevistas.

Quanto à validade da pesquisa, Hammersley apresenta as três premissas:

1. A validade do conhecimento não pode ser avaliada com certeza. Julgam-se os pressupostos tomando por base sua plausibilidade e credibilidade. 2. A existência dos fenômenos independe de nossas afirmações a seu respeito. Nossos pressupostos sobre eles podem ser apenas mais ou menos aproximados daquilo que sejam esses fenômenos. 3. A realidade torna-se acessível através das (diferentes) perspectivas sobre os fenômenos. A pesquisa visa à apresentação da realidade, e não à reprodução desta (HAMMERSLEY, 1992, p. 50-52 apud. FLICK, 2009, p. 345).

Os dados coletados, através das entrevistas realizadas, foram interpretados utilizando-se da análise de conteúdo como ferramental metodológico. Tal proposição metodológica justifica-se porque a análise de conteúdo conduz à descrição objetiva e sistemática do conteúdo de mensagem, permitindo a sua interpretação e expressões (BARDIN, 2004).

Por fim, cabe mencionar que o presente trabalho não tem como intuito estabelecer verdades irrefutáveis quanto aos resultados analisados, mas sim realizar uma interpretação mais acurada possível visando apresentar a realidade do tema.

\section{APRESENTAÇÃO E ANÁLISE DOS RESULTADOS}

Inicialmente, observou-se, através das entrevistas realizadas, uma predominância feminina no meio acadêmico, igualmente ao que ocorre com a profissão. Dos 21 entrevistados, 19 se identificaram como mulheres enquanto 2 se identificaram como homens, representando 90,5\% e 9,5\% respectivamente. A esse achado, cabe mencionar o estudo de Castro e Yamamoto (1998). Para os autores, embora a entrada da mulher no ensino superior tenha aumentado, verifica-se um número maior de matrículas 
femininas em cursos tidos como mais adequados a mulheres. Ademais, de acordo com os supracitados, de maneira geral, as profissões "femininas" ocupam um lugar de menos prestígio e menor remuneração, ainda que a mulher venha se afirmando no mercado de trabalho.

Já, quanto a idade dos entrevistados, percebeu-se uma predominância de acadêmicos que possuem entre 20 e 30 anos, (16 alunos), representando $80 \%$ do total, seguida de dois alunos com idade inferior a 20 anos, representando $10 \%$. As faixas etárias de 30 a 40 e superior a 40 anos, obtiveram separadamente um aluno, cada um representando somente $5 \%$ dos entrevistados. Ou seja, entre aqueles acadêmicos que se autoentitularam como atuantes nas áreas administrativas e secretariais, tem-se um predomínio de mulheres jovens.

Na sequência, investigaram-se, na opinião dos entrevistados, quais os requisitos que eles acreditavam serem necessários para manter a empregabilidade de um profissional de secretariado. Sobre esse aspecto observou-se que a proatividade foi citada como essencial para a manutenção da sua empregabilidade por $50 \%$ dos entrevistados. O segundo termo mais citado foi a atualização, presente na fala de $30 \%$ dos acadêmicos, justificando que "se manter atualizado é importante, seja pela busca de um mestrado e doutorado, ou seja, através das realizações de cursos profissionalizantes, como na área tecnológica" (ENTREVISTADO C, 2019). Respostas como postura, responsabilidade, ética, espírito de liderança e comprometimento também foram abordados, condizendo com as atitudes consideradas empregáveis apresentadas pelos autores previamente (SAVIANI, 1997 apud. NASCIMENTO et al., 2007; RODRIGUES et al. 2016).

No entanto, a Entrevistada E (2019) propôs uma resposta diferente da maioria, dizendo que "modo de se vestir acho que conta bastante, de uma maneira mais formal". De forma contrária, a Entrevistada F (2019) afirma que a postura profissional vale mais do que a imagem, complementado pela Entrevistada D (2019) que explica "quando você fala em secretário você já pensa em uma pessoa assim de saia e blusinha social, usando salto, acho que a própria sociedade impõe a visão de uma secretária".

A questão seguinte pedia que os entrevistados definissem boa 
aparência. A resposta mais recorrente, representando $57 \%$ da amostra, foi em relação à higiene e limpeza pessoal. Ainda, observou-se alta incidência de respostas que desprezavam a vulgaridade, como: "[...] não precisa ser elegante, mas sempre bem arrumada, não totalmente formal, mas que não seja vulgar" (ENTREVISTADA E, 2019), "uma pessoa comportada, na verdade, sem chamar atenção, sem causar escândalo" (ENTREVISTADA B, 2019), e ainda "com uma roupa adequada, não tá com nada que é muito chamativo, decotado. [...] Eu penso numa pessoa neutra porque você está no ambiente de trabalho" (ENTREVISTADA S, 2019).

Em análise aos achados através das entrevistas realizadas, evidenciase que para um percentual de acadêmicos, a visão de boa aparência difere da do mercado de trabalho, criticando inclusive algumas das exigências impostas a eles. A exemplo, pode-se citar a fala da Entrevistada K (2019) a qual sustenta que algumas organizações exigem cabelo sempre arrumado, maquiagem e roupa social. O discurso da Entrevistada M (2019) corrobora com isso ao alegar que para as empresas conservadoras, que costumam ser a maioria no Brasil, espera-se uma pessoa magra, maquiada e de cabelo liso. Dessa forma, evidencia-se aqui a teoria da discriminação racial por conta da preferência pelos cabelos lisos, e também o preconceito contra pessoas gordas.

Ainda, em relação a boa aparência, uma acadêmica expressou que não tem uma definição para o termo, já que para ela a estética não é importante, "mas se levado em consideração a opinião da sociedade, ela definitivamente não seria um exemplo de boa aparência" (ENTREVISTADA D, 2019). Em contrapartida, a Entrevistada P (2019) acredita que o termo está relacionado a vestir-se adequadamente, unhas feitas, cabelos e pele bem cuidados, além de "[...] evitar tatuagens visíveis. Acho que depende do ambiente que você trabalha, um pouco de cuidado é fundamental".

Quando questionados sobre os comportamentos esperados do secretário executivo, as palavras-chave foram ética e respeito. Nesta questão, a não ser pela única vez em que se ouviu o termo amável (ENTREVISTADA G, 2019), não se evidenciou relação com os atributos expostos anteriormente, como graciosidade, harmonia e charme (RIBEIRO, 1990; PARKER PUBLISHING COMPANY, 1981; GRION; PAZ, 1998). No entanto, vale 
destacar o discurso de uma acadêmica que afirmou ser necessário entregar mais do que se pede, e ainda

Tem que saber se impor quando é necessário, porque dependendo onde você está trabalhando, quando você está com [...] um executivo de certo nível, ele provavelmente vai te tratar como se você fosse inferior. [...] Porque você é só 'uma secretária' né, eles ainda têm essa mentalidade (ENTREVISTADA R, 2019).

Dos 21 entrevistados, 17 concordaram que os padrões estéticos e comportamentais influenciam na empregabilidade dos secretários executivos, representando aproximadamente $80 \%$. Grande parte destes afirmou que as próprias empresas já possuem um padrão definido, buscando essas características nos candidatos. Assim sendo, dada a frequente escassez de vagas no mercado de trabalho, normalmente, quem tem interesse na vaga opta por se ajustar as normas da organização (CASE, 2007).

Sobre os padrões comportamentais especificamente, a Entrevistada A (2019) relatou que "as pessoas no geral têm essa ideia predeterminada do comportamento, da conduta, dos secretários" e isso acaba influenciando no processo de seleção, confirmando a teoria sobre os estereótipos intrínsecos a profissão. O Entrevistado I (2019) acredita que o comportamento é o diferencial, e que conquistar o próprio espaço por meio da responsabilidade e trazer um bom retorno para a organização, desmistifica a apelação estética.

Entretanto, de forma contrária, muitos entrevistados afirmaram que grande parte das empresas prioriza a aparência ao conhecimento. "Para alguns empregadores a aparência interfere na contratação [...] se a empresa exige, vai fazer o que? [...] tem que se adaptar ao mercado" (ENTREVISTADA L, 2019) e "eu não acho certo, mas [a aparência] influencia. Querendo ou não você é olhado dos pés à cabeça, quando você tem o primeiro contato com a empresa e com o cliente [...] a primeira coisa que eles olham é a aparência" (ENTREVISTADA O, 2019).

Por conta destes padrões, principalmente 0 estético, alguns entrevistados apontaram já terem sido prejudicados na busca de um trabalho. $A$ Entrevistada D (2019) alegou acreditar que um concorrente dentro dos padrões, mas com uma formação inferior, teria mais chances de conseguir a vaga de trabalho do que ela, que possui tatuagens e não se veste formalmente. 
O mesmo acontece com a Entrevistada T (2019), a qual discursou que "o mercado de trabalho desde sempre exigiu a secretária engomadinha, que não tenha tatuagem, não tenha piercing. Isso foi um problema para mim, eu sinto que já perdi muita oportunidade por ter tatuagem, por ter piercing aparente."

Para o futuro, a Entrevistada U (2019) diz ter esperanças de que, com a evolução da sociedade, a aparência não seja mais um critério a ser julgado como integrante do desenvolvimento profissional. Quanto a isso, a Entrevistada $P$ acrescenta

A gente percebe que está ocorrendo uma mudança, a gente vê bastante jovens com o cabelo muito colorido [...], mas acho que dentro do ambiente organizacional ainda há resistência a isso [...] acho que ainda tem pessoas que perdem o emprego por conta do visual. Vai ser uma tendência, daqui um tempo tudo isso vai ser normal. [...] É uma questão cultural (ENTREVISTADA P, 2019).

Apesar de a maioria ter concordado que os padrões influenciam na contratação e manutenção do emprego, apenas 38\% dos entrevistados afirmaram já ter se sentido pressionado a seguir estes padrões no seu ambiente de trabalho. Evidenciou-se que as explicações mais comuns para os que negaram sentir-se pressionados a adotar determinado padrão, estão relacionadas ao fato de a empresa exigir um uniforme próprio. Outro possível motivo para os que alegaram não sofrer com os padrões estéticos ou comportamentais, pode se dar pelo fato de que esses entrevistados, de certa forma, estão de acordo com os padrões enraizados na sociedade, assim os mesmos não sentem os impactos decorrentes da discriminação.

Ainda em relação ao uniforme, vale destacar a resposta apresentada por uma acadêmica que alegou trabalhar em uma organização bem liberal quanto a estética e vestimenta, entretanto, devido ao assédio sexual sofrido, ela optou por utilizar o uniforme.

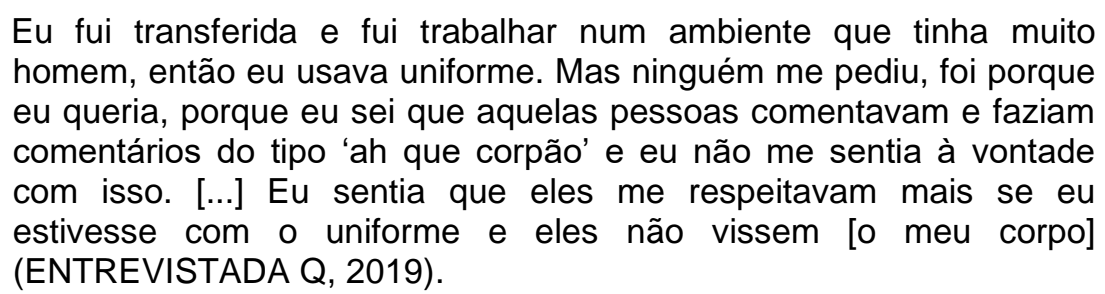

Percebeu-se uma cobrança por parte de algumas empresas para se 
enquadrar nos padrões, principalmente estéticos, porém não de forma obrigatória. Essa alegação é confirmada nas respostas "eu sinto indiretamente em olhares e algumas palavrinhas" (ENTREVISTADA U, 2019), "dependendo do jeito que você estava a pessoa te olhava com um olhar diferente" (ENTREVISTADA E, 2019), e ainda

Não existe uma obrigação [na empresa], mas eu sou uma pessoa que
não usa maquiagem sempre no dia a dia porque eu tenho alergia no
olho e me incomoda. Mas quando eu uso maquiagem no trabalho a
minha chefe me elogia [...] então eu sinto que eu deveria me maquiar
sempre, mas não é o que eu gosto, não me sinto bem, me causa
desconforto (ENTREVISTADA O, 2019).

A Entrevistada R (2019) corrobora:

Para entrar na empresa que eu estou hoje, minha aparência contou bastante, [...] a maneira como eu me visto. A minha chefe desde o primeiro dia falou "olha, eu gostaria que você se vestisse assim, sempre de saia, de salto alto" e eu me visto assim porque eu gosto, mas não é uma obrigação (ENTREVISTADA R, 2019).

Essa cobrança mascarada é o suficiente para influenciar nas decisões dos funcionários, como abordam as Entrevistadas B e E (2019), respectivamente: "tenho bastante vontade de cortar o cabelo bem curtinho, não sei se eles ligariam muito, mas eu tenho um pouco de medo sim" e "já pensei antes de fazer tatuagem que poderia ter problemas no trabalho".

Essa pressão é menos evidenciada no meio acadêmico. De acordo com os entrevistados, somente 5 pessoas afirmaram já terem se sentido prejudicados pela imposição de padrões na universidade. A Entrevistada $F$ (2019) alegou acreditar que o curso é extremamente conservador e isso "é algo que eu aprendi na prática porque eu não tinha essa visão [antes de entrar no curso]". Já a Entrevistada T (2019) confessou já ter ouvido outras acadêmicos dizendo que ela não parece alguém que cursa Secretariado Executivo pelo fato estar sempre usando tênis e sem maquiagem, e ainda acrescenta "as pessoas que são padrão, que não tem piercing, não tem tatuagem, elas têm um preconceito com as pessoas que têm". Quanto aos padrões comportamentais especificamente, um acadêmico afirmou:

Nós [acadêmicos de Secretariado Executivo] carregamos esses estigmas que devemos estar sempre bem alinhados, e ter esse "perfil secretária", como uma orientação para o mercado de trabalho. [...] Então já me senti excluído, sem credibilidade, por eu ter um 
comportamento considerado exagerado (ENTREVISTADO I, 2019).

Em contrapartida, grande maioria garantiu nunca ter percebido essa discriminação dentro dos cursos, como alegou os acadêmicos: "os professores são bem arrumados, mas eles nunca discriminaram pela roupa que você vem" (ENTREVISTADA Q, 2019); "Das pessoas de dentro [do curso] não, mas acredito que as pessoas de foram exigem, tem um olhar diferente" (ENTREVISTADA E, 2019); "no nosso curso nunca percebi isso, exceto na parte de eventos que tinha aquela questão de etiqueta, tinha que estar vestido 'assim e assado', mas no dia a dia não" (ENTREVISTADO O, 2019). Destacase o comentário da Entrevistada R (2019) a qual sustentou acreditar que deveria ter um pouco mais de cobrança estética no curso, "por ser secretariado, por conta do curso mesmo, do que a gente aprende aqui, como etiqueta", explicou.

Por fim, confrontando os estudos teóricos desenvolvidos no início da expansão da área de secretariado (GRION; PAZ, 1998; RIBEIRO, 1990) com os achados através das entrevistas realizadas, pode-se inferir que a profissão de secretariado ainda permanece envolta a inúmeros estereótipos tanto pelo mercado, quanto pelos próprios acadêmicos e profissionais da área. Essa constatação leva a necessidade urgente da área de pensar em ações para mitigar esses estereótipos e possibilitar maior empregabilidade aos profissionais formados na área.

\section{CONSIDERAÇÕES FINAIS}

Por conta das mudanças do mercado de trabalho, o profissional de secretariado executivo precisa atualizar suas habilidades e conhecimentos, de forma a manter-se empregável. Contudo, sob a hipótese de que há padrões estéticos e comportamentais como parte dos estereótipos relacionados ao Secretariado Executivo, nesta pesquisa se propôs descobrir se esses paradigmas influenciam na empregabilidade do profissional. A bibliografia apresentada demonstrou que a discriminação estética na busca por empregos não é somente um problema atual, pois existe desde a industrialização do mundo. Ainda, evidenciou-se que as profissões com a peculiaridade de front 
office e de predominância feminina, ambas características inerentes aos secretários executivos, são as mais cobradas quanto a estética.

Neste contexto, realizou-se entrevistas com acadêmicos do curso de Secretariado Executivo, especificamente da Unioeste campus de Toledo, que exerciam função administrativa ou secretarial na organização em que trabalhava, com o intuito de compreender suas percepções sobre o tema abordado. Dessa maneira, notou-se que a maioria dos entrevistados acreditam que características como, proatividade, responsabilidade e ética, são as mais importantes para a empregabilidade dos secretários executivos. Todavia, evidenciou-se 0 discernimento predominante de que grande parte das empresas preza pelos aspectos físicos, algumas vezes de forma superior aos conhecimentos e habilidades.

Muito embora, alguns entrevistados afirmaram acreditar que os aspectos físicos ainda são essenciais para os secretários executivos, a maioria dos acadêmicos expressou não concordar com a supervalorização estética. Constata-se então que o objetivo desta pesquisa foi alcançado, e que a pergunta de pesquisa foi respondida: os padrões estéticos e comportamentais inerentes ao profissional de Secretariado Executivo influenciam sim na sua empregabilidade. Isso pôde ser comprovado nos discursos da maioria dos acadêmicos entrevistados, que demonstraram haver uma cobrança dos padrões estéticos de forma muito presente na rotina de trabalho dos mesmos.

Quanto aos padrões comportamentais, estes não foram muito evidenciados pelos entrevistados, isso pode se dar pelo fato de que esses realmente não são muito frequentes no Secretariado Executivo. Entretanto, outra forma de se explicar esse fenômeno, pode ser pelo fato de que a discriminação comportamental seja ainda menos palpável do que a estética, dificultando a percepção e identificação desses por meio dos profissionais.

Discute-se muito sobre os estereótipos relacionados à profissão, no entanto, a perspectiva dos padrões estéticos e comportamentais é um tema ainda pouco abordado, o que se leva a acreditar que a presente pesquisa contribuiu muito para a área. Contudo, devido às limitações encontradas durante o processo de produção deste artigo, não foi possível abranger os acadêmicos de Secretariado Executivo em outras instituições do Brasil. Dessa 
forma, sugere-se como proposta para pesquisas futuras, a abordagem deste tema em outras regiões do país, com a finalidade de identificar se os resultados divergem quando provindos de culturas diferentes. Estimula-se também a criação de artigos que discorram sobre como a discriminação ocorre com secretários executivos já formados e que exerçam a profissão.

\section{REFERÊNCIAS}

BORIS, G. D. J. B.; CESIDIO, M. de H. Mulher, corpo e subjetividade: uma análise desde o patriarcado à contemporaneidade. Rev. Mal-Estar Subj., Fortaleza, v. 7, n. 2, p. 451- 478, set. 2007. Disponível em http://pepsic.bvsalud.org/scielo.php?script=sci_arttext\&pid=S151861482007000 $200012 \&$ Ing=pt\&nrm=iso . acessos em 04 jun. 2019.

BRASIL. Lei no 9.029 , de 13 de abril de 1995. Proíbe a exigência de atestados de gravidez e esterilização, e outras práticas discriminatórias, para efeitos admissionais ou de permanência da relação jurídica de trabalho, e dá outras providências. Brasília, DF: Presidência da República, [2015]. Disponível em: http://www.planalto.gov.br/ccivil_03/leis//9029.htm . Acesso em: 14 jun. 2019.

CARMO, A. A. do. Percepções sobre o uso de piercings e/ou tatuagens por funcionários de empreendimentos hoteleiros de Fiz do Iguaçu (Brasil). Revista Brasileira de Pesquisa em Turismo. v.5, n.1, p.83-100, abr. 2011.

CASE, T. A. Como conseguir emprego no Brasil do século XXI. São Paulo: CATHO, 2004.

CASTRO, A. E. F. de; YAMAMOTO, O. H. A Psicologia como profissão feminina: apontamentos para estudo. Estudos de Psicologia, [s.l.], v.3, n.1, p. 147-158,1998. Disponível em: http://www.scielo.br/pdf/epsic/v3n1/a11v03n1.pdf. Acesso em: 23 jun. 2019.

COLLING, A.. A construção histórica do feminino e do masculino In: STREY, M. N.; CABEDA, S. T L.; PREHN, D. R. (orgs.). Gênero e cultura: questões contemporâneas. Porto Alegre: EDIPUCRS, 2004. p. 13-38.

DAMASCENO, Ca. M. Em casa de enforcado não se fala em corda: notas sobre a construção social da boa aparência no Brasil. In: GUIMARÃES, A. S. e HUNTLEY, L. (orgs.) Tirando a Máscara: Ensaios sobre o Racismo no Brasil. São Paulo, Paz e Terra, 2000. 
FAVRETTO, V. Secretárias contra o estereótipo. Jornal Gazeta do Povo, 2009. Disponível em: https://www.gazetadopovo.com.br/economia/pos-ecarreira/secretarias-contra-oestereotipo-bynjd066oy8vughev77r233ny/. Acesso em: 30 de jun. 2019.

FLICK, U. Introdução à pesquisa qualitativa. 3. ed. Porto Alegre: Artmed, 2009 FONTANELLA, B. J. B.; RICAS, J.; TURATO, E. R. Amostragem por saturação em pesquisas qualitativas: contribuições teóricas. Cadernos de Saúde Pública. 24(1), 17-27., 2008.

GIL, A. C. Métodos e técnicas de pesquisa social. 6. ed. São Paulo: Atlas, 2008.

GRION, L. da S.; PAZ, S.. Manual prático para secretárias, comissários e modelos. 2. ed. São Paulo: Érica, 1998.

LAKOFF, R. Linguagem e lugar da mulher. In: OSTERMANN, A. C.; FONTANA, B. (orgs.). Linguagem. Gênero. Sexualidade: clássicos traduzidos. São

Paulo: Parábola Editorial, 2010. p. 9-30.

NASCIMENTO, A. F. do; et al. Carreira e empregabilidade na área secretarial. Revista Expectativa, [s.l.], v. 4, n. 1, p.21-32, jun. 2007. Disponível em: http://erevista.unioeste.br/index.php/expectativa/article/view/408 . Acesso em: 11 jun. 2019.

NASCIMENTO, G. A. F.; ALKIMIN, M. A. Limites do poder de direção do empregador e a discriminação estética na relação de emprego. In: Encontro Nacional do CONPEDI, XXII, 2013, Curitiba. Anais [...] Tema: 25 anos da constituição cidadã: Os atores sociais e a concretização sustentável dos objetivos da república. p. 49-74. Disponível em:

http://www.publicadireito.com.br/publicacao/unicuritiba/livro.php?gt=133. Acesso em: 04 jun. 2019.

OIT - ORGANIZAÇÃO INTERNACIONAL DO TRABALHO. Igualdade de gênero e raça no trabalho: avanços e desafios. Brasília: OIT, 2010

PAIM, A dos S.; PEREIRA, M. E. Aparência física, estereótipos e discriminação racial.

Ciências \& Cognição, [s.l.], v. 16, n. 1, abr. 2011. Disponível em:

http://www.cienciasecognicao.org/revista/index.php/cec/article/view/419 
Acesso em: 14 jun. 2019.

PAIM, A. dos S.; PEREIRA, M. E. Estereótipos, boa aparência e a secretária executiva.

Secretariado Executivo em Revist@, v. 6, p. 29-40, maio, 2012. Disponível em: http://seer.upf.br/index.php/ser/article/view/2098. Acesso em: 14 jun. 2019.

PARKER PUBLISHING COMPANY. Secretária de sucesso. São Paulo: Summus, 1981.

PIRES, M. R. G. M., FONSECA, R. M. G. S., PADILLA, B. Politicy of care in the criticism towards gender stereotypes. Revista Brasileira de Enfermagem, [s.l.], p-1223-1230, nov. 2016. Disponível em:

http://www.scielo.br/pdf/reben/v69n6/0034-7167-reben-69-061223.pdf. Acesso em: 05 jul. 2019.

RIBEIRO, M. W. M. Profissão: secretária. 2. ed. Porto Alegre: Ed. Ortiz, ADVB, 1990.

RODRIGUES, A. A.; et al. Empregabilidade Profissional: O Secretariado Executivo em Foco na Amazônia Setentrional. Revista de Gestão e Secretariado, [s.I.], v. 7, n. 3, p. 66-95, dez. 2016. ISSN 2178-9010. Disponível em: https://www.revistagesec.org.br/secretariado/article/view/480. Acesso em: 10 jun. 2019.

SABINO, R. F.; ROCHA, F. G. Secretariado: do estriba ao web writer. Rio de Janeiro: Brasport, 2004.

SOUSA, D. V. de; et al. Os reflexos constitucionais quanto a discriminação estética feminina no ambiente de trabalho. [2018 ou 2019]. Trabalho de Conclusão de Curso (Bacharelado em Direito) - Faculdade de Balsas, Balsas. Disponível em: encurtador.com.br/aktJN. Acesso em: 13 jun. 2019. 